\title{
Three-quarters attack rate of SARS-CoV-2 in the Brazilian Amazon during a largely unmitigated epidemic
}

\author{
Lewis F. Buss ${ }^{1 *}$, Carlos A. Prete Jr. ${ }^{2 *}$, Claudia M. M. Abrahim ${ }^{3 *}$, Alfredo Mendrone Jr. ${ }^{4,5 *}$, \\ Tassila Salomon $^{6,7 *}$, Cesar de Almeida-Neto ${ }^{4,5}$, Rafael F. O. França ${ }^{8}$, Maria C. Belotti ${ }^{2}$, \\ Maria P. S. S. Carvalho ${ }^{3}$, Allyson G. Costa ${ }^{3}$, Myuki A. E. Crispim ${ }^{3}$, Suzete C. Ferreira ${ }^{4,5}$, \\ Nelson A. Fraiji ${ }^{3}$, Susie Gurzenda ${ }^{9}$, Charles Whittaker ${ }^{10}$, Leonardo T. Kamaura ${ }^{11}$, Pedro L. Takecian ${ }^{11}$, \\ Pedro da Silva Peixoto ${ }^{11}$, Marcio K. Oikawa ${ }^{12}$, Anna S. Nishiya ${ }^{4,5}$, Vanderson Rocha ${ }^{4,5}$, \\ Nanci A. Salles ${ }^{4}$, Andreza Aruska de Souza Santos ${ }^{13}$, Martirene A. da Silva ${ }^{3}$, Brian Custer ${ }^{14,15}$, \\ Kris V. Parag ${ }^{16}$, Manoel Barral-Netto ${ }^{17}$, Moritz U. G. Kraemer ${ }^{18}$, Rafael H. M. Pereira' ${ }^{19}$, \\ Oliver G. Pybus ${ }^{18}$, Michael P. Busch ${ }^{14,15}$, Márcia C. Castro ${ }^{9}$, Christopher Dye ${ }^{18}$, Vitor H. Nascimento ${ }^{2}$, \\ Nuno R. Faria ${ }^{1,16,18} \uparrow$, Ester C. Sabino ${ }^{1} \uparrow$
}

\begin{abstract}
1Departamento de Molestias Infecciosas e Parasitarias and Instituto de Medicina Tropical da Faculdade de Medicina da Universidade de São Paulo, São Paulo, Brazil. ${ }^{2}$ Departamento de Engenharia de Sistemas Eletrônicos, Escola Politécnica da Universidade de São Paulo, São Paulo, Brazil. ${ }^{3}$ Fundação Hospitalar de Hematologia e Hemoterapia do Amazonas, Manaus, Brazil. ${ }^{4}$ Fundação Pró-Sangue-Hemocentro de São Paulo, São Paulo, Brazil. ${ }^{5}$ Laboratório de Investigação Médica em Patogênese e Terapia dirigida em Onco-Imuno-Hematologia (LIM-31), Departamento de Hematologia, Hospital das Clínicas HCFMUSP, Faculdade de Medicina da Universidade de São Paulo, São Paulo, Brazil. ${ }^{6}$ Fundação Hemominas-Fundação Centro de Hematologia e Hemoterapia de Minas Gerais, Belo Horizonte, Brazil. ${ }^{7}$ Faculdade Ciências Médicas de Minas Gerais, Belo Horizonte, Brazil. ${ }^{8}$ Department of Virology and Experimental Therapy, Institute Aggeu Magalhaes, Oswaldo Cruz Foundation, Recife, Brazil. ${ }^{9}$ Department of Global Health and Population, Harvard T. H. Chan School of Public Health, Boston, MA, USA. ${ }^{10}$ Department of Infectious Disease Epidemiology, School of Public Health, Imperial College London, London, UK. ${ }^{11}$ Institute of Mathematics and Statistics, University of São Paulo, São Paulo, Brazil. ${ }^{12}$ Center of Mathematics, Computing and Cognition-Universidade Federal do ABC, São Paulo, Brazil. ${ }^{13}$ Oxford School of Global and Area Studies, Latin American Centre, University of Oxford, Oxford, UK. ${ }^{14}$ Vitalant Research Institute, San Francisco, CA, USA. ${ }^{15}$ University of California, San Francisco, CA, USA. ${ }^{16}$ MRC Centre for Global Infectious Disease Analysis, J-IDEA, Imperial College London, London, UK. ${ }^{17}$ Instituto Gonçalo Moniz-Fundação Oswaldo Cruz (Fiocruz), Salvador, Brazil. ${ }^{18}$ Department of Zoology, University of Oxford, Oxford, UK. ${ }^{19}$ Institute for Applied Economic Research-Ipea, Brasília, Brazil.
\end{abstract}

*These authors contributed equally to this work.

†Corresponding author. Email: sabinoec@usp.br (E.C.S.); nfaria@ic.ac.uk (N.R.F.)

SARS-CoV-2 spread rapidly in the Brazilian Amazon and the attack rate there is an estimate of the final size of a largely unmitigated epidemic. We use a convenience sample of blood donors to show that by June, one month after the epidemic peak in Manaus, capital of Amazonas state, $44 \%$ of the population had detectable IgG antibodies. Correcting for cases without a detectable antibody response and antibody waning, we estimate a $66 \%$ attack rate in June, rising to $76 \%$ in October. This is higher than in São Paulo, in southeastern Brazil, where the estimated attack rate in October is $29 \%$. These results confirm that, when poorly controlled, COVID-19 can infect a high fraction of the population causing high mortality.

Brazil has experienced one of the world's most rapidlygrowing COVID-19 epidemics, with the Amazon being the worst hit region (1). Manaus is the capital and largest metropolis in the Amazon, with a population of over two million and population density of 158 inhabitants $/ \mathrm{km}^{2}$. The first SARS-CoV-2 case in Manaus was confirmed on $13^{\text {th }}$ March 2020 (2) and was followed by an explosive epidemic, peaking in early May with 4.5-fold excess mortality (3). This was followed by a sustained drop in new cases despite relaxation of non-pharmaceutical interventions (NPIs). The prevalence of antibodies against SARS-CoV-2 is an estimate of the attack rate in Manaus and provides a data-based estimate of the extent of COVID-19 spread in the absence of effective mitigation.

Given a basic reproduction number $\left(R_{0}\right)$ of $2.5-3.0$ for Amazonas state, (see (4)), the expected attack rate during an unmitigated epidemic in a homogeneously mixed population is $89-94 \%$ (5). When the percentage of infected people exceeds the herd immunity threshold of $60-67 \%$ [100 $\times(1-$ $\left.1 / R_{0}\right)$ ], each infection generates fewer than one secondary case (case reproduction number, $R_{\mathrm{t}}<1$ ) and incidence declines. The goal of this study was to measure the SARS-CoV2 attack rate in Manaus and to explore whether the epidemic was contained $\left(R_{\mathrm{t}}<1\right)$ because infection reached the herd 
immunity threshold, or because of other factors such as behavioral changes and NPIs. We compare data from Manaus with findings from Sao Paulo, where the first Brazilian COVID-19 cases were detected $(2,6)$ and the rise and fall in mortality were slower and more protracted.

We used a chemiluminescence assay (CIMA) that detects IgG antibody against the SARS-CoV-2 nucleocapsid (N) protein (Abbott, Chicago, USA). To infer the attack rate from antibody test positivity we need to account for the sensitivity and specificity of the test (7). The specificity of the CIMA is high $(>99.0 \%)(8-10)$, but previous high $(>90.0 \%)$ sensitivity estimates $(8,10)$ ) may not apply to blood donor screening $(11,12)$ for two reasons. First, most SARS-CoV-2 infections in blood donors are asymptomatic and weaker antibody responses in asymptomatic disease (13) may lead to a lower initial seroconversion rate (i.e., more "serosilent" infections). Second, due to antibody waning, sensitivity falls over time (14), such that test positivity increasingly underestimates the true attack rate.

We used a variety of clinical samples at different time points to gain insight into the dynamics of the anti-N IgG detected by the Abbott CIMA (Fig. 1). In samples from COVID-19 hospitalized patients collected at 20-33 days post symptom onset, reflecting high disease severity and optimal timing of blood collection, sensitivity was $91.8 \%$ (95\% confidence interval, CI, $80.8 \%$ to $96.8 \%$ ), suggesting that $\sim 8 \%$ of severe convalescent cases do not develop detectable antibodies. Among a cohort of symptomatic cases with mild disease also tested in the early convalescent period, sensitivity fell to $84.5 \%$ (95\% CI $78.7 \%$ to $88.9 \%$ ) - indicating initial seroconversion is lower in milder cases. In samples drawn later (50 to 131 days) from the same mild disease cohort, sensitivity was lower still $(80.4 \%, 95 \%$ CI $71.8 \%$ to $86.8 \%)$, reflecting antibody waning. Indeed, in a subset of 104 patients with two consecutive blood draws, the signal-to-cutoff (S/C) declined over the period observed (Fig. 1B) and among 88 individuals with a positive reading at the first time point, the mean rate of decay was $-0.9 \log _{2} \mathrm{~S} / \mathrm{C}$ units every 100 days (95\% CI -1.1 to -0.75$)$, equating to a half-life of 106 days (95\% CI 89 to 132 days) (Fig. 1C).

Finally, we tested 1,000 blood donations given in São Paulo in July 2020 in parallel using a second high-specificity (>99.0\% (15)) immunoassay less prone to antibody waning (14). (Roche Elecsys, Rotkreuz, Switzerland). One-hundred and three samples were positive using the Abbott CIMA and an additional 30 were positive using the Roche assay. Assuming all 133 samples were true positives the sensitivity of the Abbott N IgG assay was $77.4 \%$ (95\% CI $69.6 \%$ to $83.7 \%$ ) on asymptomatic blood donor samples. As samples in July were donated four months into the ongoing epidemic in São Paulo, the false negatives using the Abbott assay include both cases that did not initially seroconvert, as well as past infections that had subsequently seroreverted.

Because specificity was high, with only one falsepositive result in 821 pre-epidemic donations from Manaus (Fig. 1A), we also attempted to improve assay performance by reducing the threshold for a positive result from $1.4 \mathrm{~S} / \mathrm{C}$ (as per the manufacturer) to $0.4 \mathrm{~S} / \mathrm{C}$. This resulted in 27 false-positives and a specificity of $96.7 \%$, but substantially improved sensitivities at this threshold as shown in Fig. 1A and table S1.

In order to estimate the proportion of the population with IgG antibodies against SARS-CoV-2, we used a convenience sample of routine blood donations made at the Fundação Pró-Sangue blood bank in São Paulo and the Fundação Hospitalar de Hematologia e Hemoterapia do Amazonas (HEMOAM) in Manaus. The monthly sample size and sampling dates, spanning February to October, are shown in table $\mathrm{S} 2$.

The prevalence of SARS-CoV-2 antibodies in February and March was low $(<1 \%)$ in both São Paulo and Manaus. This is consistent with the timing of the first confirmed cases that were diagnosed on $13^{\text {th }}$ March in Manaus, and on the $25^{\text {th }}$ of February in São Paulo (2). In Manaus, after adjustment for the sensitivity and specificity of the test (but not antibody waning), and re-weighting for age and sex, the prevalence of SARS-CoV-2 IgG antibodies was 4.8\% (95\% CI $3.3 \%$ to $6.8 \%$ ) in April, $44.5 \%$ (95\% CI $39.2 \%$ to $50.0 \%$ ) in May, reaching a peak of $52.5 \%$ (47.6\% to $57.5 \%$ ) in June (Fig. 2 and table S2). The increasing seroprevalence closely followed the curve of cumulative deaths. In São Paulo the prevalence of SARS-CoV-2 IgG in blood donors also increased steadily, reaching $13.6 \%$ (95\% CI $12.0 \%$ to $8.1 \%$ ) in June.

Between June and October, the effect of seroreversion became apparent in both cities. In Manaus, following the peak antibody prevalence in June, the proportion of blood donors that tested positive fell steadily to $25.8 \%$ in October. Excluding extreme negative samples $(<0.4 \mathrm{~S} / \mathrm{C})$, the median assay signal fell steadily from May: 3.9 (May), 3.5 (June), 2.3 (July), 1.7 (August), 1.4 (September), and 1.3 (October) (Fig. 2B). Similarly, in São Paulo antibody prevalence remained stable between June and October, while the number of daily COVID-19 deaths also remained relatively stable, reflecting a balance between antibody waning from infections earlier in the outbreak and seroconversions following recent infections (Fig. 2C).

In Manaus, the effect of antibody waning on apparent prevalence was partially ameliorated by reducing the threshold for a positive result from $1.4 \mathrm{~S} / \mathrm{C}$ to $0.4 \mathrm{~S} / \mathrm{C}$ and correcting for the resulting increased false-positive rate. However, the results in São Paulo were largely unchanged by this correction (Fig. 2 and table S2).

We further correct for seroreversion with a model-based 
approach (see supplementary materials). Briefly, we assume that the probability of remaining seropositive decays exponentially from the time of recovery. We estimate the decay rate and the proportion of patients that serorevert using the seroprevalence data from Manaus to find the minimum decay rate that minimizes the number of new cases in July and August while avoiding decreases in prevalence - i.e., assuming there were few cases in Manaus in July and August and changes in seroprevalence were due mainly to waning antibodies. The results of these corrections are shown in Fig. 2 and table S2. After adjusting for seroreversion, we find that cumulative incidence in Manaus may have reached as high as $66.2 \%$ (95\% CI $61.5 \%$ to $80.1 \%$ ) in July and $76.0 \%$ (95\% CI $66.6 \%$ to $97.9 \%$ ) in October. Although this is the minimum prevalence estimate allowed by the exponential decay model, and should therefore be conservative, in the absence of an accepted approach to account for seroreversion, these results should be interpreted with caution. The reliability of this estimate depends on the validity of the exponential decay assumption.

To calculate infection fatality ratios (IFRs) we used the age-sex and sensitivity-specificity adjusted prevalence in June, as this was following the epidemic peak in Manaus, but before significant seroreversion. In Manaus, the IFRs were $0.17 \%$ and $0.28 \%$, considering PCR confirmed COVID19 deaths and probable COVID-19 deaths based on syndromic identification, respectively; whereas in São Paulo, the global IFRs were $0.46 \%$ and $0.72 \%$, respectively. The difference may be explained by an older population structure in São Paulo (fig. S1A). Supporting this inference, the agespecific IFRs were similar in the two cities, and similar to estimates based on data from China (16) (fig. S1B) and a recent systematic review (17). We also obtained similar agespecific IFRs using the seroreversion-corrected prevalence estimates from October (fig. S1).

Blood donors may not be representative of the wider population. The eligible age range for blood donation in Brazil (16 - 69yr), as well as sex distributions in donors, are different from the underlying populations in both cities (fig. S2). Re-weighting our estimates for age and sex (Fig. 2 and table $\mathrm{S} 2$ ) resulted in a slight reduction in prevalence, particularly in Manaus, where men were overrepresented among donors and also had a higher seroprevalence (fig. S3). Selfreported ethnicity was similar in donors to the census populations (fig. S2). The median income in blood donors' census tracts of residence was marginally higher than a populationweighted average for both cities (fig. S4). Regarding the spatial distribution of donors, there was a similar antibody prevalence across different regions sampled in both cities (fig. S5), and we achieved good geographic coverage in both cities (see supplementary materials and fig. S5).

Because potential donors are deferred if they have a positive SARS-CoV-2 PCR or clinical diagnosis of COVID-19, increasing access to testing might have reduced the pool of eligible donors through time. However, only $2.7 \%$ of residents in Manaus and $8.5 \%$ in São Paulo reported having a PCR test performed by September (fig. S6). As such, changing access to testing is unlikely to have been important. Considering these factors together, we suggest that our results can be cautiously extrapolated to the population aged 16-69yr in Manaus and São Paulo. Within this group, blood donors may underestimate the true exposure to SARS-CoV-2 due to a potentially higher socioeconomic profile, deferral of symptomatic donors, and the possibility of greater health awareness and engagement among those that donate blood. However, it is likely that seroprevalence in children and older adults is lower.

Our results show that between $44 \%$ and $66 \%$ of the population of Manaus was infected with SARS-CoV-2 by July, following the epidemic peak there. The lower estimate does not account for false-negative cases or antibody waning; the upper estimate accounts for both. $R_{\mathrm{t}}$ fell $<1$ (fig. $\mathrm{S} 7$ ) in late April when cumulative infections were between 5\% and $46 \%$ of the population. NPIs (table S3) were implemented in mid to late March when physical distancing also increased (fig. S8). It is likely that these factors worked in tandem with growing population immunity to contain the epidemic. Transmission has since continued in Manaus, albeit at a lower level than in April-May (Fig. 2 and fig. S7). From the second week of August there has been a small increase in the number of cases (18) which, at the time of writing, has begun to decline. Consequently, the attack rate rose to $76 \%$ in October. This remains lower than predicted in a homogeneously-mixed population with no mitigation strategies ( 90\%). Homogeneous mixing is unlikely to be a valid assumption (19) and behavioral change and NPIs may explain why the estimated final epidemic size has not yet reached $89-94 \%$ as expected for $R_{0}$ values between $2.5-3.0$ (4).

By 1st October, Manaus recorded 2,642 (1,193/million inhabitants [mil]) COVID-19 confirmed deaths and 3,789 $(1,710 / \mathrm{mil})$ severe acute respiratory syndrome deaths; São Paulo recorded 12,988 (1,070/mil) and 20,063 (1,652/mil), respectively. The cumulative mortality proportions were similar in both cities and high compared to other locations - e.g., United Kingdom (620/mil), France (490/mil) or the United States $(625 / \mathrm{mil})$, as of Oct $1^{\text {st }}(20)$. The different attack rates in Manaus and São Paulo (76\% versus $29 \%$ of people infected), despite similar overall mortality rates, are due to the higher IFR in São Paulo. The age-standardized mortality ratio was 2.0 comparing observed deaths in Manaus to those expected projecting the age-specific mortality in São Paulo on the age structure of Manaus. The $R_{0}$ was similar in the two cities (fig. S7) but cases and deaths in- 
creased then decreased more slowly in São Paulo than Manaus where the rise and fall was more abrupt (fig. S7). The lower attack rate in São Paulo is partly explained by the larger population size (2.2 versus 12.2 million inhabitants). As population size increases, the time to reach a given attack rate also increases (21).

The attack rate in Manaus is higher than estimates based on seroprevalence studies conducted in Europe and North America $(8,22,23)$, and recent results from Kenyan blood donors (24). A similarly high seroprevalence ( 50\%) was observed in slums in Mumbai, India (25). In Brazil, one population-based serosurvey in São Paulo (26) found a similar prevalence to our study (26.2\% versus $28.8 \%$ in blood donors, in October). In Manaus, a lower seroprevalence (14\%, in June) was found in a random household sample of 250 people (1). But this study was not powered at the city level and used the lower sensitivity Wondfo (27) rapid test. As such, the results are not be directly comparable.

Future investigations should be conducted to investigate what accounted for such extensive transmission of SARS-CoV-2 in Manaus. Possible explanations include socioeconomic conditions, household crowding (28), limited access to clean water, and reliance on high-transmission risk boat travel (1) in which over-crowding results in accelerated contagion, similar to that seen on cruise ships (29). The young mobile population with potentially low preexisting immunity to SARS-CoV-2 (30), as well as the early circulation of multiple virus lineages introduced from multiple locations may have contributed to the large scale of the outbreak.

In conclusion, our data show that $>70 \%$ of the population has been infected in Manaus approximately seven months after the virus first arrived in the city. This is above the theoretical herd immunity threshold. However, prior infection may not confer long-lasting immunity $(30,31)$. Indeed, we observed rapid antibody waning in Manaus, consistent with other reports that have shown signal waning on the Abbott IgG assay $(14,32)$. However, other commercial assays, with different designs or targeting different antigens, have more stable signal (14), and there is evidence for a robust neutralizing antibody response several months out from infection (33). Rare reports of reinfection have been confirmed (34), but the frequency of its occurrence remains an open question (35). Manaus represents a "sentinel" population, giving us a data-based indication of what may happen if SARS-CoV-2 is allowed to spread largely unmitigated. Further seroepidemiological, molecular and genomic surveillance studies in the region are required urgently to determine the longevity of population immunity, the correlation with the observed antibody waning and the diversity of circulating lineages. Monitoring of new cases and the ratio of local versus imported cases will also be vital to understand the extent to which population immunity might prevent future transmission, and the potential need for booster vaccinations to bolster protective immunity.

\section{REFERENCES AND NOTES}

1. P. C. Hallal, F. P. Hartwig, B. L. Horta, M. F. Silveira, C. J. Struchiner, L. P. Vidaletti, N. A. Neumann, L. C. Pellanda, O. A. Dellagostin, M. N. Burattini, G. D. Victora, A. M. B. Menezes, F. C. Barros, A. J. D. Barros, C. G. Victora, SARS-CoV-2 antibody prevalence in Brazil: Results from two successive nationwide serological household surveys. Lancet Glob. Health 8, e1390-e1398 (2020). doi:10.1016/S2214-109X(20)30387-9 Medline

2. D. da S. Candido, I. M. Claro, J. G. de Jesus, W. M. Souza, F. R. R. Moreira, S. Dellicour, T. A. Mellan, L. du Plessis, R. H. M. Pereira, F. C. S. Sales, E. R. Manuli, J. Thézé, L. Almeida, M. T. Menezes, C. M. Voloch, M. J. Fumagalli, T. M. Coletti, C. A. M. da Silva, M. S. Ramundo, M. R. Amorim, H. H. Hoeltgebaum, S. Mishra, M. S. Gill, L. M. Carvalho, L. F. Buss, C. A. Prete, J. Ashworth, H. I. Nakaya, P. S. Peixoto, O. J. Brady, S. M. Nicholls, A. Tanuri, Á. D. Rossi, C. K. V. Braga, A. L. Gerber, A. P. de C. Guimarães, N. Gaburo, C. S. Alencar, A. C. S. Ferreira, C. X. Lima, J. E. Levi, C. Granato, G. M. Ferreira, R. S. Francisco, F. Granja, M. T. Garcia, M. L. Moretti, M. W. Perroud, T. M. P. P. Castiñeiras, C. S. Lazari, S. C. Hill, A. A. de Souza-Santos, C. L. Simeoni, J. Forato, A. C. Sposito, A. Z. Schreiber, M. N. N. Santos, C. Z. de Sá, R. P. Souza, L. C. Resende-Moreira, M. M. Teixeira, J. Hubner, P. A. F. Leme, R. G. Moreira, M. L. Nogueira, Brazil-UK Centre for Arbovirus Discovery, Diagnosis, Genomics and Epidemiology (CADDE) Genomic Network, N. M. Ferguson, S. F. Costa, J. L. Proenca-Modena, A. T. R. Vasconcelos, S. Bhatt, P. Lemey, C.-H. Wu, A. Rambaut, N. J. Loman, R. S. Aguiar, O. G. Pybus, E. C. Sabino, N. R. Faria, Evolution and epidemic spread of SARS-CoV-2 in Brazil. Science 369, 1255-1260 (2020). doi:10.1126/science.abd2161

3. J. D. Y. Orellana, G. M. da Cunha, L. Marrero, B. L. Horta, I. da Costa Leite, Explosão da mortalidade no epicentro amazônico da epidemia de COVID-19. Cad. Saude Publica 36, e00120020 (2020). doi:10.1590/0102-311×00120020 Medline

4. W. M. de Souza, L. F. Buss, D. da S. Candido, J.-P. Carrera, S. Li, A. E. Zarebski, R. H. M. Pereira, C. A. Prete Jr., A. A. de Souza-Santos, K. V. Parag, M. C. T. D. Belotti, M. F. Vincenti-Gonzalez, J. Messina, F. C. da Silva Sales, P. D. S. Andrade, V. H. Nascimento, F. Ghilardi, L. Abade, B. Gutierrez, M. U. G. Kraemer, C. K. V. Braga, R. S. Aguiar, N. Alexander, P. Mayaud, O. J. Brady, I. Marcilio, N. Gouveia, G. Li, A. Tami, S. B. de Oliveira, V. B. G. Porto, F. Ganem, W. A. F. de Almeida, F. F. S. T. Fantinato, E. M. Macário, W. K. de Oliveira, M. L. Nogueira, O. G. Pybus, C.-H. Wu, J. Croda, E. C. Sabino, N. R. Faria, Epidemiological and clinical characteristics of the COVID-19 epidemic in Brazil. Nat. Hum. Behav. 4, 856-865 (2020). doi:10.1038/s41562-020-0928-4 Medline

5. J. Ma, D. J. D. Earn, Generality of the final size formula for an epidemic of a newly invading infectious disease. Bull. Math. Biol. 68, 679-702 (2006). doi:10.1007/s11538-005-9047-7 Medline

6. J. G. de Jesus, C. Sacchi, D. da S. Candido, I. M. Claro, F. C. S. Sales, E. R. Manuli, D. B. B. da Silva, T. M. de Paiva, M. A. B. Pinho, K. C. de O. Santos, S. C. Hill, R. S. Aguiar, F. Romero, F. C. P. dos Santos, C. R. Gonçalves, M. do C. Timenetsky, J. Quick, J. H. R. Croda, W. de Oliveira, A. Rambaut, O. G. Pybus, N. J. Loman, E. C. Sabino, N. R. Faria, Importation and early local transmission of COVID-19 in Brazil, 2020. Rev. Inst. Med. Trop. São Paulo 62, e30 (2020). doi:10.1590/s16789946202062030

7. F. I. Lewis, P. R. Torgerson, A tutorial in estimating the prevalence of disease in humans and animals in the absence of a gold standard diagnostic. Emerg. Themes Epidemiol. 9, 9 (2012). doi:10.1186/1742-7622-9-9 Medline

8. A. Bryan, G. Pepper, M. H. Wener, S. L. Fink, C. Morishima, A. Chaudhary, K. R. Jerome, P. C. Mathias, A. L. Greninger, Performance Characteristics of the Abbott Architect SARS-CoV-2 IgG Assay and Seroprevalence in Boise, Idaho. J. Clin. Microbiol. 58, e00941-20 (2020). doi:10.1128/JCM.00941-20

9. Public Health England, "Evaluation of Abbott SARS-CoV-2 IgG assay for the detection of anti-SARS-CoV-2 antibodies" (2020); 
www.gov.uk/government/publications/covid-19-laboratory-evaluations-ofserological-assays.

10. D. L. Ng, G. M. Goldgof, B. R. Shy, A. G. Levine, J. Balcerek, S. P. Bapat, J. Prostko, M. Rodgers, K. Coller, S. Pearce, S. Franz, L. Du, M. Stone, S. K. Pillai, A. Sotomayor-Gonzalez, V. Servellita, C. S. S. Martin, A. Granados, D. R. Glasner, L. M. Han, K. Truong, N. Akagi, D. N. Nguyen, N. M. Neumann, D. Qazi, E. Hsu, W. Gu, Y. A. Santos, B. Custer, V. Green, P. Williamson, N. K. Hills, C. M. Lu, J. D. Whitman, S. L. Stramer, C. Wang, K. Reyes, J. M. C. Hakim, K. Sujishi, F. Alazzeh, L. Pham, E. Thornborrow, C.-Y. Oon, S. Miller, T. Kurtz, G. Simmons, J. Hackett Jr., M. P. Busch, C. Y. Chiu, SARS-CoV-2 seroprevalence and neutralizing activity in donor and patient blood. Nat. Commun. 11, 4698 (2020). doi:10.1038/s41467020-18468-8 Medline

11. D. W. Eyre, S. F. Lumley, D. O'Donnell, N. E. Stoesser, P. C. Matthews, A. Howarth, S. B. Hatch, B. D. Marsden, S. Cox, T. James, R. Cornall, D. I. Stuart, G. Screaton, D. Ebner, D. W. Crook, C. P. Conlon, K. Jeffery, T. M. Walker, T. E. Peto, Stringent thresholds for SARS-CoV-2 IgG assays result in under-detection of cases reporting loss of taste/smell. medRxiv 20159038 [preprint]. 25 July 2020.

12. F. Hamilton, P. Muir, M. Attwood, A. N. B. Vipond, R. Hopes, E. Moran, N. Maskell, D. Warwick, M. Albur, J. Turner, A. MacGowan, D. Arnold, Kinetics and performance of the Abbott architect SARS-CoV-2 IgG antibody assay. J. Infect. 10.1016/j.jinf.2020.07.031 (2020). doi:10.1016/j.jinf.2020.07.031 Medline

13. Q.-X. Long, X.-J. Tang, Q.-L. Shi, Q. Li, H.-J. Deng, J. Yuan, J.-L. Hu, W. Xu, Y. Zhang, F.-J. Lv, K. Su, F. Zhang, J. Gong, B. Wu, X.-M. Liu, J.-J. Li, J.-F. Qiu, J. Chen, A.-L. Huang, Clinical and immunological assessment of asymptomatic SARS-CoV-2 infections. Nat. Med. 26, 1200-1204 (2020). doi:10.1038/s41591020-0965-6 Medline

14. F. Muecksch, H. Wise, B. Batchelor, M. Squires, E. Semple, C. Richardson, J. McGuire, S. Clearly, E. Furrie, N. Greig, G. Hay, K. Templeton, J. C. C. Lorenzi, T. Hatziioannou, S. Jenks, P. D. Bieniasz, Longitudinal analysis of serology and neutralizing antibody levels in COVID19 convalescents. J. Infect. Dis. jiaa659 (2020). doi:10.1093/infdis/iiaa659

15. Public Health England, "Evaluation of Roche Elecsys Anti-SARS-CoV-2 serology assay for the detection of anti-SARS-CoV-2 antibodies" (2020);

www.gov.uk/government/publications/covid-19-laboratory-evaluations-ofserological-assays.

16. R. Verity, L. C. Okell, I. Dorigatti, P. Winskill, C. Whittaker, N. Imai, G. CuomoDannenburg, H. Thompson, P. G. T. Walker, H. Fu, A. Dighe, J. T. Griffin, M. Baguelin, S. Bhatia, A. Boonyasiri, A. Cori, Z. Cucunubá, R. FitzJohn, K. Gaythorpe, W. Green, A. Hamlet, W. Hinsley, D. Laydon, G. Nedjati-Gilani, S. Riley, S. van Elsland, E. Volz, H. Wang, Y. Wang, X. Xi, C. A. Donnelly, A. C. Ghani, N. M. Ferguson, Estimates of the severity of coronavirus disease 2019: A modelbased analysis. Lancet Infect. Dis. 20, 669-677 (2020). doi:10.1016/S14733099(20)30243-7 Medline

17. N. Brazeau, R. Verity, S. Jenks, H. Fu, C. Whittaker, P. Winskill, I. Dorigatti, P. Walker, S. Riley, R. Schnekenberg, H. Heltgebaum, T. Mellan, S. Mishra, H. Unwin, O. Watson, Z. Cucunuba Perez, M. Baguelin, L. Whittles, S. Bhatt, A. Ghani, N. Ferguson, L. Okell, "Report 34: COVID-19 infection fatality ratio: estimates from seroprevalence" (Imperial College London, 2020). doi:10.25561/83545

18. MAVE, Grupo de Métodos Analíticos em Vigilância Epidemiológica (PROCC/Fiocruz e EMAp/FGV), Resumo do Boletim InfoGripe-Semana Epidemiológica (SE) 42; https://gitlab.procc.fiocruz.br/mave/repo/tree/master/Boletins\%20do\%20In foGripe.

19. T. Britton, F. Ball, P. Trapman, A mathematical model reveals the influence of population heterogeneity on herd immunity to SARS-CoV-2. Science 369, 846849 (2020). doi:10.1126/science. abc6810 Medline

20. Our World in Data, “Coronavirus Pandemic (COVID-19)" (2020); https://ourworldindata.org/coronavirus.

21. B. Ridenhour, J. M. Kowalik, D. K. Shay, Unraveling Ro: Considerations for public health applications. Am. J. Public Health 104, e32-e41 (2014).
doi:10.2105/AJPH.2013.301704 Medline

22. M. Pollán, B. Pérez-Gómez, R. Pastor-Barriuso, J. Oteo, M. A. Hernán, M. PérezOlmeda, J. L. Sanmartín, A. Fernández-García, I. Cruz, N. Fernández de Larrea, M. Molina, F. Rodríguez-Cabrera, M. Martín, P. Merino-Amador, J. León Paniagua, J. F. Muñoz-Montalvo, F. Blanco, R. Yotti, Prevalence of SARS-CoV-2 in Spain (ENE-COVID): A nationwide, population-based seroepidemiological study. Lancet 396, 535-544 (2020). doi:10.1016/S0140-6736(20)31483-5 Medline

23. S. Stringhini, A. Wisniak, G. Piumatti, A. S. Azman, S. A. Lauer, H. Baysson, D. De Ridder, D. Petrovic, S. Schrempft, K. Marcus, S. Yerly, I. Arm Vernez, O. Keiser, S. Hurst, K. M. Posfay-Barbe, D. Trono, D. Pittet, L. Gétaz, F. Chappuis, I. Eckerle, N. Vuilleumier, B. Meyer, A. Flahault, L. Kaiser, I. Guessous, Seroprevalence of antiSARS-CoV-2 IgG antibodies in Geneva, Switzerland (SEROCoV-POP): A population-based study. Lancet 396, 313-319 (2020). doi:10.1016/S01406736(20)31304-0 Medline

24. S. Uyoga, I. M. O. Adetifa, H. K. Karanja, J. Nyagwange, J. Tuju, P. Wanjiku, R. Aman, M. Mwangangi, P. Amoth, K. Kasera, W. Ng'ang'a, C. Rombo, C. Yegon, K. Kithi, E. Odhiambo, T. Rotich, I. Orgut, S. Kihara, M. Otiende, C. Bottomley, Z. N. Mupe, E. W. Kagucia, K. E. Gallagher, A. Etyang, S. Voller, J. N. Gitonga, D. Mugo, C. N. Agoti, E. Otieno, L. Ndwiga, T. Lambe, D. Wright, E. Barasa, B. Tsofa, P. Bejon, L. I. Ochola-Oyier, A. Agweyu, J. A. G. Scott, G. M. Warimwe, Seroprevalence of anti-SARS-CoV-2 IgG antibodies in Kenyan blood donors. Science 10.1126/science.eabe1916 (2020). doi:10.1126/science.abe1916 Medline

25. A. Malani, D. Shah, G. Kang, G. N. Lobo, J. Shastri, M. Mohanan, R. Jain, S. Agrawal, S. Juneja, S. Imad, U. Kolthur-Seetharam, Seroprevalence of SARSCoV-2 in slums versus non-slums in Mumbai, India. Lancet Glob. Health 10.1016/S2214-109X(20)30467-8 (2020). doi:10.1016/S2214-109X(20)30467$\underline{8}$ Medline

26. SoroEpi MSP: Serial soroepidemiological survey to monitor the prevalence of SARS-CoV-2 infection in the Municipality of São Paulo, SP, Brazil (2020); www.monitoramentocovid19.org/.

27. V. A. dos Santos, M. M. Rafael, E. C. Sabino, A. J. da S. Duarte, Sensitivity of the Wondfo One Step COVID-19 test using serum samples. Clinics 75, e2013 (2020). doi:10.6061/clinics/2020/e2013 Medline

28. B. Rader, S. V. Scarpino, A. Nande, A. L. Hill, B. Adlam, R. C. Reiner, D. M. Pigott, B. Gutierrez, A. E. Zarebski, M. Shrestha, J. S. Brownstein, M. C. Castro, C. Dye, H. Tian, O. G. Pybus, M. U. G. Kraemer, Crowding and the shape of COVID-19 epidemics. Nat. Med. 10.1038/s41591-020-1104-0 (2020). doi:10.1038/s41591020-1104-0 Medline

29. K. Mizumoto, K. Kagaya, A. Zarebski, G. Chowell, Estimating the asymptomatic proportion of coronavirus disease 2019 (COVID-19) cases on board the Diamond Princess cruise ship, Yokohama, Japan, 2020. Euro Surveill. 25, 2000180 (2020). doi:10.2807/1560-7917.ES.2020.25.10.2000180 Medline

30. A. W. D. Edridge, J. Kaczorowska, A. C. R. Hoste, M. Bakker, M. Klein, K. Loens, M. F. Jebbink, A. Matser, C. M. Kinsella, P. Rueda, M. leven, H. Goossens, M. Prins, P. Sastre, M. Deijs, L. van der Hoek, Seasonal coronavirus protective immunity is short-lasting. Nat. Med. 26, 1691-1693 (2020). doi:10.1038/s41591-020-1083-1 Medline

31. K. A. Callow, H. F. Parry, M. Sergeant, D. A. J. Tyrrell, The time course of the immune response to experimental coronavirus infection of man. Epidemiol. Infect. 105, 435-446 (1990). doi:10.1017/S0950268800048019 Medline

32. S. F. Lumley et al., The duration, dynamics and determinants of SARS-CoV-2 antibody responses in individual healthcare workers. medRxiv 20224824 [preprint]. 4 November 2020.

33. A. Wajnberg, F. Amanat, A. Firpo, D. R. Altman, M. J. Bailey, M. Mansour, M. McMahon, P. Meade, D. R. Mendu, K. Muellers, D. Stadlbauer, K. Stone, S. Strohmeier, V. Simon, J. Aberg, D. L. Reich, F. Krammer, C. Cordon-Cardo, Robust neutralizing antibodies to SARS-CoV-2 infection persist for months. Science 370, 1227-1230 (2020). doi:10.1126/science.abd7728 Medline

34. K. K.-W. To, I. F.-N. Hung, J. D. Ip, A. W.-H. Chu, W.-M. Chan, A. R. Tam, C. H.-Y. Fong, S. Yuan, H.-W. Tsoi, A. C.-K. Ng, L. L.-Y. Lee, P. Wan, E. Y.-K. Tso, W.-K. To, D. N.-C. Tsang, K.-H. Chan, J.-D. Huang, K.-H. Kok, V. C.-C. Cheng, K.-Y. Yuen, 
Coronavirus Disease 2019 (COVID-19) Re-infection by a Phylogenetically Distinct Severe Acute Respiratory Syndrome Coronavirus 2 Strain Confirmed by Whole Genome Sequencing. Clin. Infect. Dis. ciaa1275 (2020). doi:10.1093/cid/ciaa1275 Medline

35. J. Shaman, M. Galanti, Will SARS-CoV-2 become endemic? Science 370, $527-$ 529 (2020). doi:10.1126/science.abe5960 Medline

36. Data and code for "Three-quarters attack rate of SARS-CoV-2 in the Brazilian Amazon during a largely unmitigated epidemic"; doi:doi.org/10.5061/dryad.c59zw3r5n.

37. P. J. Diggle, Estimating Prevalence Using an Imperfect Test. Epidemiol. Res. Int. 2011, 608719 (2011). doi:10.1155/2011/608719

38. W. J. Rogan, B. Gladen, Estimating prevalence from the results of a screening test. Am. J. Epidemiol. 107, 71-76 (1978). doi:10.1093/oxfordjournals.aje.al12510 Medline

39. K. Parag, C. Donnelly, Optimising Renewal Models for Real-Time Epidemic Prediction and Estimation. bioRxiv 835181 [preprint]. 8 November 2019.

40. N. Ferguson, D. Laydon, G. Nedjati Gilani, N. Imai, K. Ainslie, M. Baguelin, S. Bhatia, A. Boonyasiri, Z. Cucunuba Perez, G. Cuomo-Dannenburg, A. Dighe, I. Dorigatti, H. Fu, K. Gaythorpe, W. Green, A. Hamlet, W. Hinsley, L. Okell, S. Van Elsland, H. Thompson, R. Verity, E. Volz, H. Wang, Y. Wang, P. Walker, P. Winskill, C. Whittaker, C. Donnelly, S. Riley, A. Ghani, "Report 9: Impact of nonpharmaceutical interventions (NPIs) to reduce COVID19 mortality and healthcare demand" (Imperial College London, 2020). doi:10.25561/77482

41. K. V. Parag, Improved estimation of time-varying reproduction numbers at low case incidence and between epidemic waves. medRxiv 20194589 [preprint]. 18 September 2020.

\section{ACKNOWLEDGMENTS}

Funding: This study was supported by the Itau Unibanco Todos pela Saude program and by CADDE/FAPESP (MR/S0195/1 and FAPESP 18/14389-0)

(http://caddecentre.org/). NRF is supported by a Wellcome Trust and Royal Society Sir Henry Dale Fellowship (204311/Z/16/Z). We acknowledge the National Heart, Lung, and Blood Institute of the US National Institutes of Health Recipient Epidemiology and Donor Evaluation Study (REDS, now in its $4^{\text {th }}$ phase, REDS-IV-P) for providing the blood donor demographic and zip code data for analysis (grant number HHSN268201100007I). We acknowledge support from UK Medical Research Council under a concordat with the UK Department for International Development and Community Jameel and the NIHR Health Protection Research Unit in Modelling Methodology. Author contributions: Conception - MBN, LFB, MC, BC, CAN, NRF, SCF, AMJ, ASN, RHMP, VR, ECS, NAS, TS, MAS and CW. Acquisition - ACMM, MPSSC, AGC, MAEC, CAN, AASS, NRF, SCF, NAF, PLT, AMJ, MKO, NV, RHMP, VR, ECS, NAS, TS, PSP, and MAS. Analysis - LFB, CAN, RHMP, CW, ECS, CAP, KVP, VHN, and MCB. Interpretation - ACMM, LFB, MPSSC, AGC, MAEC, CAN, NRF, NAF, ECS, MAS, CW, CD, MUGK, OP, VHN; drafting - LFB, ECS; revising - all authors; funding MBN, AGC, BC, NRF, NAF, ECS, NAS. Competing interests: The authors declare no competing interests. Data and materials availability: The data and code required to reproduce the results in this article can be found on Dryad (36). This project was approved by the Brazilian national research ethics committee, CONEP CAAE 30178220.3.1001.0068. This work is licensed under a Creative Commons Attribution 4.0 International (CC BY 4.0) license, which permits unrestricted use, distribution, and reproduction in any medium, provided the original work is properly cited. To view a copy of this license, visit https://creativecommons.org/licenses/by/4.0/. This license does not apply to figures/photos/artwork or other content included in the article that is credited to a third party; obtain authorization from the rights holder before using such material.

\section{SUPPLEMENTARY MATERIALS}

science.sciencemag.org/cgi/content/full/science.abe9728/DC1

Materials and Methods

Figs. S1 to 59

Tables S1 to S3

References (37-41)

28 September 2020; accepted 2 December 2020

Published online 8 December 2020

10.1126/science.abe9728 


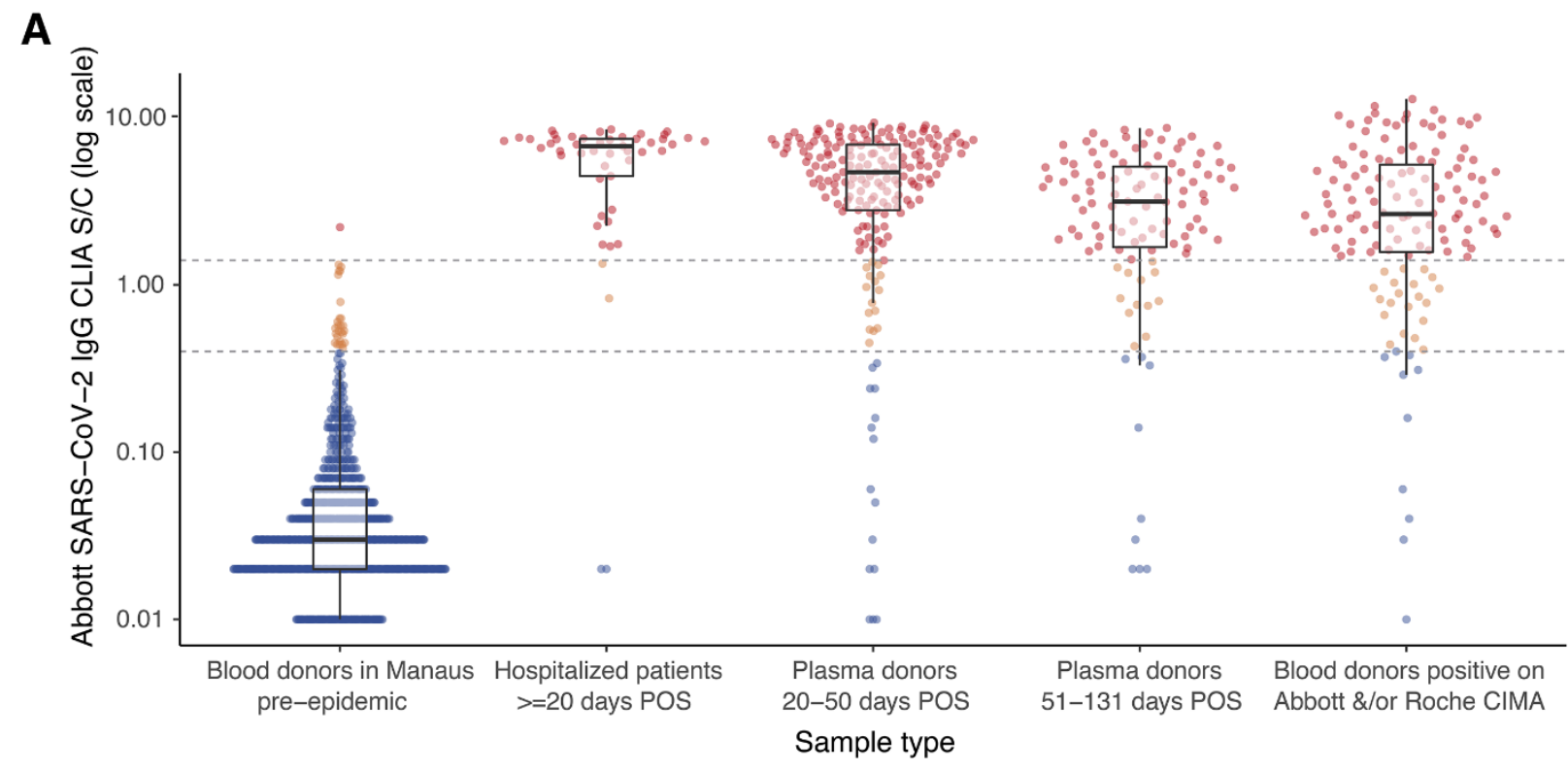

B

C
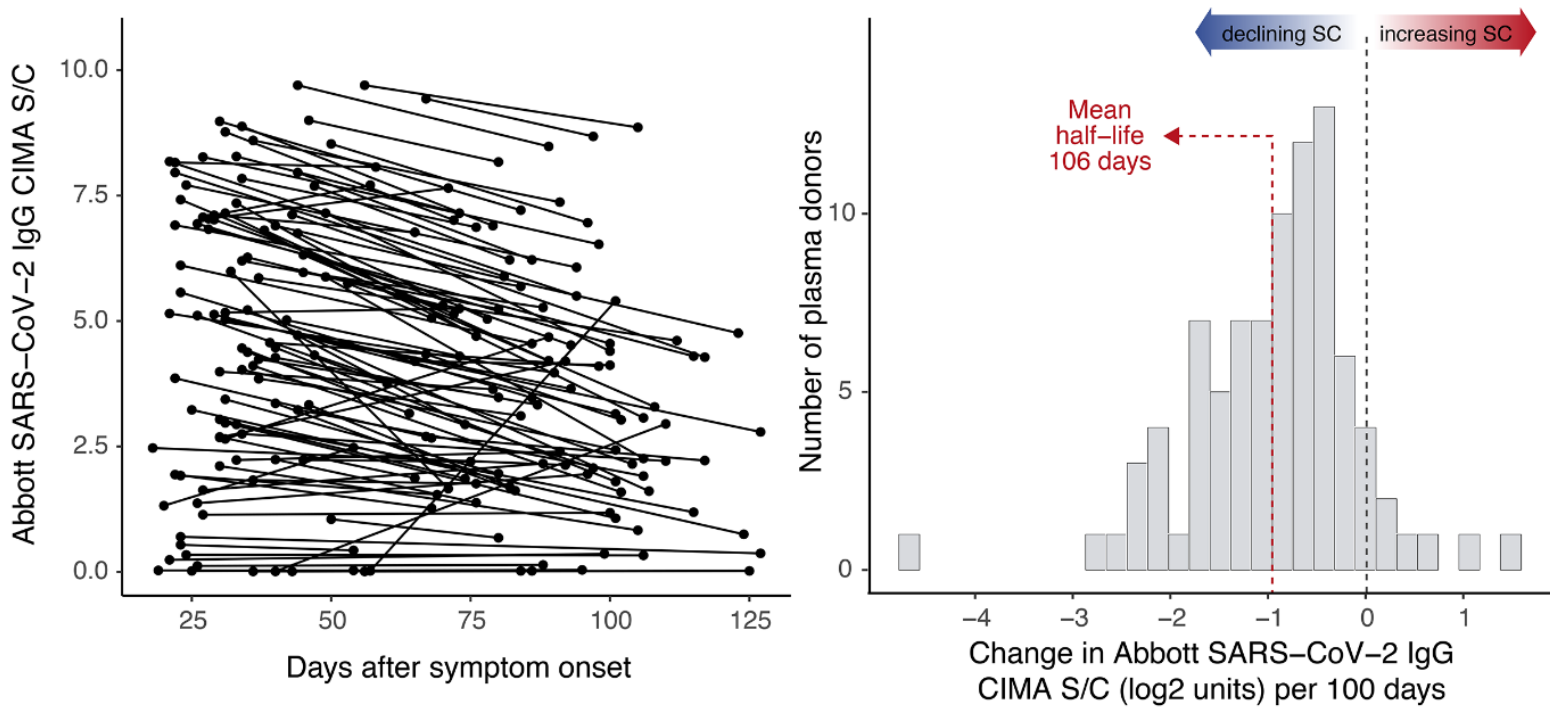

Fig. 1. Abbott SARS-CoV-2 N IgG chemiluminescence assay performance and antibody dynamics in different clinical samples. (A) Signal-to-cutoff (S/C) values using the Abbott chemiluminescence assay (CIMA) in the following clinical samples (from left to right): 821 routine blood donation samples from Manaus in February 2020, >1 month prior to the first notified case in the city; 49 samples collected at 20-33 days after symptom onset from SARS-CoV-2-PCR positive patients in São Paulo requiring hospital care; 193 patients in São Paulo with PCR-confirmed symptomatic COVID-19 not requiring hospital care, with plasma donation samples taken in the early convalescent period; 107 samples from the same non-hospitalized plasma donor cohort from the late convalescent period; 133 samples that tested positive on either the Abbott CIMA or the Roche Elecsys assay out of 1,000 routine blood donations collected in July 2020 and tested in parallel from the Fundação Pró-Sangue blood center (São Paulo). Upper dashed line manufacturer's threshold for positive result of $1.4 \mathrm{~S} / \mathrm{C}$; lower dashed line - alternative threshold of $0.4 \mathrm{~S} / \mathrm{C}$. Box plots of Abbott IgG CIMA S/C central line is the median; upper and lower hinges are the $25^{\text {th }}$ and $75^{\text {th }}$ centiles, respectively; whiskers show the range, extending to a maximum of 1.5 times interquartile range from hinge. (B) $\mathrm{S} / \mathrm{C}$ values of the Abbott CIMA for 104 convalescent plasma donors who were sampled at two different times. (C) Histogram of the slopes among 88 individuals shown in $(B)$ that tested positive $(>1.4 \mathrm{~S} / \mathrm{C})$ at the first time point. POS = post onset of symptoms. 

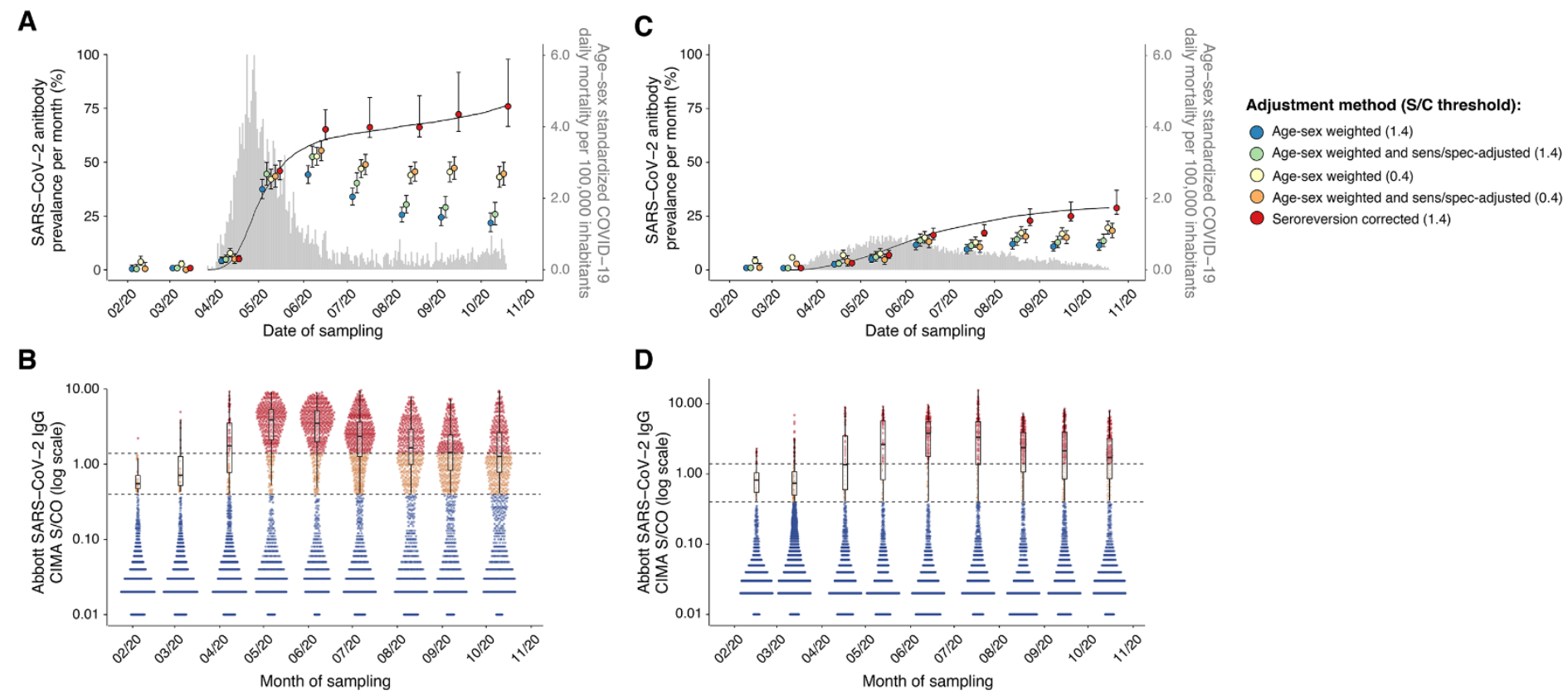

Fig. 2. Monthly antibody prevalence and signal-to-cutoff $(\mathrm{S} / \mathrm{C})$ reading in Manaus and São Paulo. (A and C) SARSCoV-2 antibody prevalence estimates in Manaus (A) and São Paulo (C) with a range of corrections, from left to right: reweighting positive tests, at positivity threshold of $1.4 \mathrm{~S} / \mathrm{C}$, to the age-sex distribution of each city; further correcting for sensitivity and specificity at this assay threshold; re-weighting positive tests at for age and sex at a reduced threshold of $0.4 \mathrm{~S} / \mathrm{C}$; correcting for sensitivity and specificity at this threshold; finally correcting for seroreversion. Error bars are 95\% confidence intervals. Grey bars are standardized daily mortality using confirmed COVID-19 deaths from the SIVEPGripe (https://covid.saude.gov.br/) notification system and standardized by the direct method using the total projected Brazilian population for 2020 as reference. Black lines are rescaled cumulative deaths, such that the maximum is set to the maximum seroprevalence estimate for each city. Mortality data are plotted according to the date of death. (B and D) Distribution of $S / C$ values over the seven monthly samples are shown for Manaus (B) and São Paulo (D). Each point represents the $\mathrm{S} / \mathrm{C}$ reading for a single donation sample. Upper dashed line - manufacturer's threshold (1.4 S/C units); lower dashed line - alternative threshold (0.4 S/C units); black boxplots show the median (central lines), interquartile range (hinges) and range extending to 1.5 times the interquartile range from each hinge (whiskers) of $\mathrm{S} / \mathrm{C}$ values above 0.4 (i.e., excluding very low and likely true-negative values). 